\title{
Resistência ao nematoide das galhas em progênies de coentro
}

\section{Progeny coriander resistant root-knot nematode}

\author{
Ana Maria Maciel dos Santos ${ }^{l} ;$ Kleyton Danilo da Silva Costa ${ }^{2 *}$; Tâmara Rebecca Albuquerque de Oliveira ${ }^{3}$; José Wilson da \\ Silva $^{4}$; Ênio Gomes Flôr Souza ${ }^{5}$; José Luiz Sandes de Carvalho Filho ${ }^{6}$
}

Resumo: O coentro possui grande importância socioeconômica para o Brasil, sendo bastante consumido como condimento e ocupa uma vasta área de cultivo, principalmente nas regiões Norte e Nordeste do país. Porém, a meloidoginose é uma das doenças que afetam a cultura, causando danos e prejuízos econômicos. Devido à escassez de pesquisas que identifiquem genótipos de coentro resistentes a nematoides, foi realizado o presente trabalho, visando avaliar o comportamento de uma população de coentro tolerante ao calor, quanto a resistência à Meloidogyne incognita raça 1. Foram avaliadas 46 progênies de meios-irmãos em delineamento de blocos ao acaso, com três repetições, sendo a parcela constituída por seis plantas. Após 15 dias da semeadura, foi realizada a inoculação de 1500 ovos do patógeno por planta e a colheita ocorreu 45 dias após a inoculação. As características avaliadas foram incidência de galhas, número de galhas no sistema radicular lavado e o número de ovos por planta. Com exceção do caráter incidência de galhas, todos os demais apresentaram diferença significativa pelo teste F, possibilitando a seleção de 31 progênies de acordo com a escala proposta por Oostenbrink. As correlações fenotípicas e genéticas do caráter número de galhas no sistema radicular foram significativas com número de ovos.

Palavras-chave: Coriandrum sativum L.; Meloidogyne incognita; Melhoramento vegetal.

Abstract: Coriander is a important vegetable crop in Brazil, being widely consumed as a condiment and cultivated mainly in North and Northeast brasilian regions. Diseases caused by Meloidogyne species are one main causers damages of crop. In the literature there is no reported about identification nematoid resistant coriander genotypes. In this study was carried the reaction evaluation of a heat-tolerant coriander population regarding resistance to Meloidogyne incognita race 1. Forty-six progenies of half-sibs were evaluated in a randomized block design, with three replications, the plot consisting of six plants. After 15 days of sowing the plants were inoculated using 1500 eggs of pathogen per plant. Evaluation occurred 45 days after inoculation, where evaluated characteristics were galls incidence, number of galls in washed root system and number of eggs per plant. Excepting incidence of galls, all variables presented significant difference by the $\mathrm{F}$ test, allowing the selection of 31 progenies according to the scale proposed by Oostenbrink. Phenotypic and genetic correlations between number of galls in root system and number of eggs were significant.

Key words: Coriandrum sativum L.; Meloidogyne incognita race 1; Plant breeding.

\footnotetext{
*Autor para correspondência

Recebido para publicação em 27/11/2017; aprovado em 23/03/2018

${ }^{1}$ Enga. Agro. Doutoranda em Melhoramento Genético de Plantas, Universidade Federal Rural de Pernambuco , R. Manuel de Medeiros, s/n - Dois Irmãos, Recife, Pernambuco; CEP: 52171-900. E-mail: agrom1960@yahoo.com.br

${ }^{2}$ Professor Doutor do Instituto Federal de Alagoas. E-mail: kd.agro@ gmail.com

${ }^{3}$ Enga. Agro. Doutoranda em Genética e Melhoramento de Plantas, Universidade Estadual do Norte Fluminense Darcy Ribeiro. E-mail: tamara_rebecca@hotmail.com

${ }^{4}$ Professor Doutor da Universidade Federal Rural de Pernambuco. E-mail: jwsamaral@hotmail.com

${ }^{5}$ Professor Doutor do Instituto Federal de Alagoas. E-mail: eniosouzape@gmail.com

${ }^{6}$ Professor Doutor da Universidade Federal Rural de Pernambuco. E-mail: jose.luiz@depa.ufrpe.br
} 


\section{INTRODUÇÃO}

O gênero Coriandrum inclui a espécie cultivada Coriandrum sativum e a espécie selvagem Coriandrum tordylium (DIEDERICHSEN, 1996). O coentro (C. sativum L.) é uma planta herbácea e anual com ciclo de vida variando de três a quatro meses, oriundo da região do Mediterrâneo. Apresenta diversas utilidades, sendo suas folhas e frutos utilizados na composição de pratos e temperos que fazem parte da culinária de diversos países (ALMEIDA, 2006). Além disso, são utilizados na indústria de alimentos, farmacêutica, na medicina (SAMOJLIK et al., 2010) e na indústria de perfumaria (NEFFATI et al., 2011).

O cultivo do coentro no Brasil é realizado por pequenos e médios produtores, em hortas familiares visando à produção de folhas e frutos, que são comercializados em feiras livres e supermercados (OLIVEIRA et al., 2005). Esta folhosa possui grande importância socioeconômica, porém, vários fatores são limitantes ao cultivo, entre eles as doenças. Os nematoides são patógenos que afetam diversas partes das plantas causando perdas e prejuízos econômicos.

Os fitonematoides do gênero Meloidogyne incitam a formação de galhas nas raízes e causam redução na absorção de nutrientes e translocação de água, resultando em menor desenvolvimento da parte aérea da planta (TIHOHOD, 2000). Esse gênero ataca diversas espécies cultivadas como a alface (FERREIRA et al., 2013), a abóbora, abobrinha, alcachofra, batata, batata-doce, berinjela, beterraba, cenoura, chicória, chuchu, ervilha, gengibre, inhame, jiló, melancia, melão, pepino, pimenta, quiabo (OLIVEIRA, 2007); entre outras culturas.

As espécies de nematoides das galhas com maior destaque na agricultura por serem mais cosmopolitas e polífagas são $M$. arenaria, $M$. hapla, $M$. incognita e $M$. javanica, sendo as duas últimas consideradas as de maior importância econômica no mundo. Em todos os continentes o M. incognita apresenta nível de relevância econômica máxima (FERRAZ; BROWN, 2016).

No coentro, a meloidoginose caracteriza-se pela presença de galhas isoladas de pequenas dimensões, que ocorre ao longo das raízes e apresentam geralmente apenas uma fêmea por galha, e muitas vezes exibe massa de ovos externa ao tecido vegetal, devido ao calibre das raízes que são quase capilares. As cultivares Palmeira, Verdão e Português são boas hospedeiras do Meloidogyne incognita raça 1 (BIONDI et al., 2001). Diniz (2012) verificou em Minas Gerais, sob cultivo protegido, que a cultivar Verdão apresenta maior resistência se comparada as cultivares Palmeira e Português, e que a raça 1 do patógeno é mais promissora para ser utilizada em programas de melhoramento genético da cultura, pois em avaliação possibilitou a identificação de genótipos de coentro com níveis superiores de variabilidade para resistência.

Os nematoides das galhas podem ser controlados através da aplicação de nematicidas, que serão progressivamente excluídos devido a efeitos adversos causados à saúde humana e ao meio ambiente (WESEMAEL et al., 2011). Para a cultura do coentro as principais medidas de controle de nematoides, como os pertencentes ao gênero Meloidogyne, são: prevenção, rotação de culturas, alqueive, uso de plantas antagonistas, eliminação de restos culturais e tigueras, eliminação de plantas daninhas, uso da manipueira, utilização de matéria orgânica, solarização, controle biológico e o uso de cultivares resistentes (PINHEIRO; PEREIRA, 2016).

Como o coentro é uma espécie alógama, as populações são constituídas por diferentes genótipos em equilíbrio, que proporcionam uma determinada média à população, havendo indivíduos que apresentam maior resistência à $M$. incognita raça 1. Por meio da seleção entre e dentro de progênies de meios-irmãos é possível selecionar genótipos superiores em populações segregantes de coentro. Neste método de melhoramento, as plantas são utilizadas como genitores femininos constituindo cada planta uma progênie de meiosirmãos (sabe-se quem é o genitor feminino mas o genitor masculino é desconhecido) sendo a seleção baseada na comparação das médias das progênies (BORÉM; MIRANDA, 2013).

A avaliação de populações obtidas da cultivar Verdão é uma estratégia para obtenção de genótipos resistentes ao patógeno (DINIZ, 2012). Isto motiva a utilização deste genótipo para obtenção das progênies utilizadas no presente programa de melhoramento, além de ser a cultivar mais explorada atualmente pelos agricultores das regiões Norte e Nordeste do Brasil.

Com isso, o presente trabalho objetivou-se avaliar o comportamento de uma população melhorada de coentro quanto a resistência à $M$. incognita raça 1 , a partir da avaliação entre progênies de meios-irmãos.

\section{MATERIAL E MÉTODOS}

O trabalho foi conduzido no Departamento de Agronomia da Universidade Federal Rural de Pernambuco (UFRPE) com localização a $8^{\circ} 54^{\prime} 47^{\prime}$ 'S, 3454'47' 'W, altitude de $6 \mathrm{~m}$, no período de outubro a dezembro de 2013, em casa de vegetação fechada com telado antiafídico nas laterais e coberta com filme de polietileno transparente de 150 micras. Durante o experimento, as médias mensais registradas pela estação meteorológica do Recife Curado (automática) para temperatura máxima, nos meses de outubro, novembro e dezembro, foram respectivamente 29,$5 ; 29,9$ e $30,7{ }^{\circ} \mathrm{C}$; enquanto que as médias apresentadas para a temperatura mínima foram respectivamente de 22,$8 ; 23,2$ e $23,2{ }^{\circ} \mathrm{C}$ (INMET, 2016).

O experimento foi conduzido em blocos casualizados com três repetições, sendo a parcela constituída por seis plantas. Os tratamentos foram 46 progênies de meios-irmãos $\mathrm{C}_{4}$ de coentro, obtidas a partir de três ciclos seletivos para tolerância ao pendoamento precoce, sendo a população inicial advinda da cultivar Verdão. Tais progênies foram selecionadas como as mais resistentes ao pendoamento, sendo por isso, escolhidas para fazer parte do presente estudo, buscando agregar mais características desejáveis a tais genótipos constituintes da coleção do programa de melhoramento genético de coentro da UFRPE. A escolha dos materiais foi baseada no fato de não haver cultivar de coentro resistente ao $M$. incognita raça 1, e segundo Diniz (2012), a avaliação de populações obtidas da cultivar Verdão é uma estratégia para obtenção de genótipos resistentes ao patógeno.

Em cada bloco foi adicionada seis plantas de tomateiro (Solanum lycopersicum L.) cultivar Santa Clara, que é padrão de suscetibilidade aos nematoides das galhas, tendo por finalidade verificar a eficiência do inóculo utilizado.

A semeadura foi realizada em bandejas de poliestireno expandido de 128 células, contendo substrato comercial a 
base de casca de pinus; turfa; carvão; vermiculita; NPK e micronutrientes; realizou-se a semeadura a $1,0 \mathrm{~cm}$ de profundidade, colocando-se três frutos de coentro ou três sementes de tomate por célula, sendo o desbaste realizado após a emergência quando as plântulas apresentaram a primeira folha definitiva, deixando-se uma plântula por célula.

Aos 15 dias após a semeadura, com o auxílio de seringa, foi realizada a inoculação de 1500 ovos por célula a uma distância de aproximadamente $0,5 \mathrm{~cm}$ do colo da plântula, diretamente no substrato. O inóculo foi obtido de fontes mantidas em tomateiros, cultivar Santa Clara. Para extração dos ovos do $M$. incognita raça 1 utilizou-se a metodologia proposta por Hussey e Barker (1973) e modificada por Boneti e Ferraz (1981).

Nas duas primeiras semanas após a inoculação, o fornecimento de água foi limitado para evitar a perda dos ovos. Em seguida, a irrigação foi realizada manualmente a depender da necessidade hídrica da cultura. Após a emergência, realizou-se fertirrigação com solução nutritiva

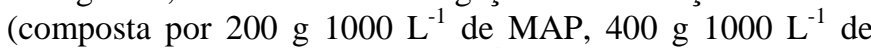
Sulfato de Magnésio, 25 g $1000 \mathrm{~L}^{-1}$ de Quelatec, $25 \mathrm{~g} 1000 \mathrm{~L}^{-}$ ${ }^{1}$ de Ultraferro, 750 g $1000 \mathrm{~L}^{-1}$ de Nitrato de Cálcio e $450 \mathrm{~g}$ $1000 \mathrm{~L}^{-1}$ de Nitrato de Potássio) três dias por semana para suprir as necessidades nutricionais das plantas ao longo do experimento.

A avaliação do experimento foi realizada 45 dias após a inoculação, determinando-se a incidência de galhas (contagem do número de galhas no sistema radicular exposto no torrão), em seguida efetuou-se a remoção do substrato aderido ao sistema radicular por meio de lavagem em água parada. Posteriormente foram quantificadas as galhas presentes em todo o sistema radicular e procedeu-se a extração dos ovos presente na raiz de cada planta, isoladamente, segundo a metodologia proposta por Hussey e Barker (1973) e modificada por Boneti e Ferraz (1981). Na quantificação do número de ovos utilizou-se a placa de Peters e microscópio com o aumento de $40 \mathrm{x}$.

Os dados obtidos para todas as variáveis foram transformados por $\sqrt{x}$, adequando-se as pressuposições da análise de variância. Realizou-se a análise de variância e as médias das variáveis com diferenças significativas pelo teste de F das 46 progênies foram comparadas pelo teste de ScottKnott a $5 \%$ de significância. Além disso, estimaram-se os parâmetros genéticos, as correlações genéticas, fenotípicas e ambientais e o coeficiente de coincidência entre os caracteres avaliados. Todos os procedimentos forma realizados pelo aplicativo computacional Genes (CRUZ, 2013).

Para verificar a reação das progênies de coentro ao $M$. incognita raça 1 foi utilizada a escala de Oostenbrink (1966) sendo consideradas resistentes as progênies com fator de reprodução $(\mathrm{FR})<1$ e susceptíveis as que apresentarem FR > 1. O FR é o quociente entre a população final (Pf) e inicial do nematoide $(\mathrm{Pi})$.

\section{RESULTADOS E DISCUSSÃO}

Não houve diferença significativa para o caráter incidência de galhas (IG), tendo os demais apresentado diferença significativa pelo teste $\mathrm{F}$ a $1,0 \%$ de significância. Os coeficientes de variação experimental oscilaram entre 10,88 (número de ovos) e 35,71 (incidência de galhas); aproximado-se dos observados por Diniz (2012) sendo inferiores para número de ovos $(10,88 \%)$ e fator de reprodução $(10,90 \%)$.

Tabela 1. Parâmetros genéticos estimados para os caracteres incidência de galhas (IG), número de galhas no sistema radicular (NGSR), número de ovos (NO) e fator de reprodução (FR) em progênies de meios-irmãos de coentro, inoculadas com Meloidogyne incognita raça 1.

\begin{tabular}{ccccc}
\hline Parâmetros & IG & NGSR & NO & \\
& & & & FR \\
\hline $\mathrm{V}_{\mathrm{g}}$ & 0,17 & 0,56 & 123,49 & 0,083 \\
$\mathrm{~V}_{\mathrm{ad}}$ & 0,17 & 0,56 & 123,49 & 0,083 \\
$\mathrm{~V}_{\mathrm{a}}$ & 1,54 & 2,09 & 22,44 & 0,014 \\
$\mathrm{~V}_{\mathrm{f}}$ & 1,71 & 2,65 & 145,93 & 0,097 \\
$\mathrm{~h}^{2}$ & 0,37 & 0,61 & 0,98 & 0,98 \\
$\mathrm{CV}_{\mathrm{g}}$ & 15,7 & 19,9 & 45,87 & 8,92 \\
$\mathrm{CV}_{\mathrm{a}}$ & 33,2 & 25,3 & 8,18 & 8,20 \\
$\mathrm{CV}_{\mathrm{g}} \mathrm{CV}_{\mathrm{a}}$ & 0,47 & 0,79 & 5,61 & 5,60 \\
\hline
\end{tabular}

Variância genética $\left(\mathrm{V}_{\mathrm{g}}\right)$, variância genética aditiva $\left(\mathrm{V}_{\mathrm{ad}}\right)$, variância ambiental $\left(\mathrm{V}_{\mathrm{a}}\right)$, variância fenotípica $\left(\mathrm{V}_{\mathrm{f}}\right)$, herdabilidade $\left(\mathrm{h}^{2}\right)$, coeficiente de variação genética $\left(\mathrm{CV}_{\mathrm{g}}\right)$, coeficiente de variação ambiental $\left(\mathrm{CV}_{\mathrm{a}}\right)$ e razão entre coeficiente de variação genética e ambiental $\left(\mathrm{CV}_{\mathrm{g}} / \mathrm{CV}_{\mathrm{a}}\right)$.

As maiores estimativas de variância genéticas foram para o número de ovos e fator de reprodução, evidenciando a possibilidade de seleção para melhoria da resistência ao patógeno nesta população (Tabela 1). Embora a variância genética para número de galhas no sistema radicular não tenha sido tão alta quanto as anteriores, possibilitou uma herdabilidade alta $(0,61)$, desta forma, a variável pode ser explorada na seleção de genótipos superiores. Segundo Oliveira et al. (2015) quanto maior a variação genética existente, maiores as possibilidades de ganhos genéticos com a seleção. Como foram obtidas altas variâncias genéticas para as maioria das variáveis em estudos é possível à obtenção de ganhos na população, além disso, para todas as variáveis analisadas toda a variância genética é devida à ação de aditividade, fato evidenciado pelos valores de variâncias aditivas, que são equivalentes aos obtidos para a variância genética. Desta forma, a seleção é facilitada, já que os efeitos devido à aditividade possibilita a manutenção da média, assim, à seleção de genótipos com maior resistência ao nematoide das galhas irá promover a obtenção de populações superiores, geração após geração.

As razões entre $\mathrm{CVg} / \mathrm{CV}$ a foram próxima ou superior a 1,00 para as variáveis em estudo, exceto para a variável incidência de galhas $(0,47)$, indicando a inviabilidade desta variável para a seleção de genótipos superiores, fato respaldado pela baixa herdabilidade $(0,37)$ obtida para a 
variável em questão. De acordo com Faluba et al., (2010) quando a relação $\mathrm{CVg} / \mathrm{CVe}$ atinge valores próximos ou superiores a 1,00 associada a altos valores de herdabilidade indicam o sucesso na seleção de genótipos superiores.

Na comparação das médias dos caracteres em estudo, observou-se a formação de dois grupos, tanto para número de ovos (NO) quanto para o fator de reprodução (FR). Para o NO, médias iguais ou inferiores a 532,23 não diferiram entre si, formando um grupo, enquanto que médias acima de 532,23 formaram o segundo grupo. Quanto ao FR, o comportamento foi semelhante, onde as médias iguais ou inferiores a 0,36 não diferiram entre si, formando um grupo, enquanto que médias acima de 0,36 formaram o segundo grupo. Todas as progênies apresentaram valores de FR inferior ao obtido para a cultivar Verdão por Biondi (2001) que foi igual a 3,23 em plantas inoculadas com 1.000 ovos planta $^{-1}$, cultivadas em vaso de 2 L e avaliadas 60 dias após a inoculação (Tabela 2).

Tabela 2. Reação de progênies de meios-irmãos de coentro em casa de vegetação ao M. incognita raça 1.

\begin{tabular}{|c|c|c|c|c|c|}
\hline Progênies & $\mathrm{IG}$ & NGSR & $\mathrm{NO}$ & FR & Reações $^{1}$ \\
\hline 1 & $18,06 \mathrm{a}$ & $35,64 \mathrm{a}$ & $337,09 \mathrm{~b}$ & $0,22 \mathrm{~b}$ & $\mathrm{R}$ \\
\hline 2 & $4,54 \mathrm{a}$ & $4,54 \mathrm{a}$ & $204,49 \mathrm{~b}$ & $0,14 \mathrm{~b}$ & $\mathrm{R}$ \\
\hline 3 & $6,05 \mathrm{a}$ & $11,49 \mathrm{a}$ & $1325,69 a$ & $0,89 \mathrm{a}$ & $\mathrm{R}$ \\
\hline 4 & $14,21 \mathrm{a}$ & $5,91 \mathrm{a}$ & $1387,56 \mathrm{a}$ & $0,92 \mathrm{a}$ & $\mathrm{R}$ \\
\hline 5 & $12,32 \mathrm{a}$ & $19,80 \mathrm{a}$ & $962,24 \mathrm{a}$ & $0,64 \mathrm{a}$ & $\mathrm{R}$ \\
\hline 6 & $2,66 \mathrm{a}$ & $14,21 \mathrm{a}$ & $153,26 \mathrm{~b}$ & $0,10 \mathrm{~b}$ & $\mathrm{R}$ \\
\hline 7 & $7,51 \mathrm{a}$ & $41,09 \mathrm{a}$ & $287,98 \mathrm{~b}$ & $0,19 \mathrm{~b}$ & $\mathrm{R}$ \\
\hline 8 & $9,49 \mathrm{a}$ & $12,32 \mathrm{a}$ & $480,49 \mathrm{~b}$ & $0,33 \mathrm{~b}$ & $\mathrm{R}$ \\
\hline 9 & $6,35 \mathrm{a}$ & $20,50 \mathrm{a}$ & $353,82 \mathrm{~b}$ & $0,24 \mathrm{~b}$ & $\mathrm{R}$ \\
\hline 10 & $8,24 \mathrm{a}$ & $2,66 \mathrm{a}$ & $320,41 \mathrm{~b}$ & $0,21 \mathrm{~b}$ & $\mathrm{R}$ \\
\hline 11 & $8,07 \mathrm{a}$ & $6,10 \mathrm{a}$ & $106,50 \mathrm{~b}$ & $0,07 \mathrm{~b}$ & $\mathrm{R}$ \\
\hline 12 & $2,07 \mathrm{a}$ & $7,51 \mathrm{a}$ & $59,14 \mathrm{~b}$ & $0,04 \mathrm{~b}$ & $\mathrm{R}$ \\
\hline 13 & $5,24 \mathrm{a}$ & $21,25 \mathrm{a}$ & $247,75 \mathrm{~b}$ & $0,17 \mathrm{~b}$ & $\mathrm{R}$ \\
\hline 14 & $3,53 \mathrm{a}$ & 9,49 a & $271,59 \mathrm{~b}$ & $0,19 \mathrm{~b}$ & $\mathrm{R}$ \\
\hline 15 & $9,30 \mathrm{a}$ & $14,44 \mathrm{a}$ & $310,11 \mathrm{~b}$ & $0,21 \mathrm{~b}$ & $\mathrm{R}$ \\
\hline 16 & $11,63 \mathrm{a}$ & $6,35 \mathrm{a}$ & $324,36 \mathrm{~b}$ & $0,22 \mathrm{~b}$ & $\mathrm{R}$ \\
\hline 17 & 4,29 a & $17,39 \mathrm{a}$ & $263,09 \mathrm{~b}$ & $0,18 \mathrm{~b}$ & $\mathrm{R}$ \\
\hline 18 & $4,54 \mathrm{a}$ & $8,24 \mathrm{a}$ & $270,93 \mathrm{~b}$ & $0,19 \mathrm{~b}$ & $\mathrm{R}$ \\
\hline 19 & $6,10 \mathrm{a}$ & $18,15 \mathrm{a}$ & $532,23 \mathrm{a}$ & $0,36 \mathrm{~b}$ & $\mathrm{R}$ \\
\hline 20 & $2,47 \mathrm{a}$ & $8,07 \mathrm{a}$ & $52,56 \mathrm{~b}$ & $0,04 \mathrm{~b}$ & $\mathrm{R}$ \\
\hline 21 & $5,24 \mathrm{a}$ & $10 \mathrm{a}$ & $274,23 \mathrm{~b}$ & $0,19 \mathrm{~b}$ & $\mathrm{R}$ \\
\hline 22 & $3,88 \mathrm{a}$ & $2,07 \mathrm{a}$ & $1442,48 \mathrm{a}$ & $0,96 \mathrm{a}$ & $\mathrm{R}$ \\
\hline 23 & $4,67 \mathrm{a}$ & $4,93 \mathrm{a}$ & $1384,58 \mathrm{a}$ & $0,92 \mathrm{a}$ & $\mathrm{R}$ \\
\hline 24 & $15,13 \mathrm{a}$ & $5,24 \mathrm{a}$ & $233,78 \mathrm{~b}$ & $0,16 \mathrm{~b}$ & $\mathrm{R}$ \\
\hline 25 & $8,59 \mathrm{a}$ & $6,45 \mathrm{a}$ & $1500,01 \mathrm{a}$ & $1,00 \mathrm{a}$ & $\mathrm{S}$ \\
\hline 26 & $5,02 \mathrm{a}$ & $3,53 \mathrm{a}$ & $310,82 \mathrm{~b}$ & $0,21 \mathrm{~b}$ & $\mathrm{R}$ \\
\hline 27 & $4,41 \mathrm{a}$ & $8,24 \mathrm{a}$ & $295,84 \mathrm{~b}$ & $0,19 \mathrm{~b}$ & $\mathrm{R}$ \\
\hline 28 & $5,38 \mathrm{a}$ & $9,30 \mathrm{a}$ & $330,88 \mathrm{~b}$ & $0,22 b$ & $\mathrm{R}$ \\
\hline 29 & $12,89 \mathrm{a}$ & $14,98 \mathrm{a}$ & $1583,24 \mathrm{a}$ & $1,06 \mathrm{a}$ & $\mathrm{S}$ \\
\hline 30 & $6,45 \mathrm{a}$ & $11,63 \mathrm{a}$ & $424,36 \mathrm{~b}$ & $0,28 \mathrm{~b}$ & $\mathrm{R}$ \\
\hline 31 & $5,25 \mathrm{a}$ & $15,92 \mathrm{a}$ & $352,69 \mathrm{~b}$ & $0,23 \mathrm{~b}$ & $\mathrm{R}$ \\
\hline 32 & $9,55 \mathrm{a}$ & $4,24 \mathrm{a}$ & $390,46 \mathrm{~b}$ & $0,26 \mathrm{~b}$ & $\mathrm{R}$ \\
\hline 33 & $9,92 \mathrm{a}$ & $6,25 \mathrm{a}$ & $281,57 \mathrm{~b}$ & $0,19 \mathrm{~b}$ & $\mathrm{R}$ \\
\hline 34 & $2,92 \mathrm{a}$ & $4,54 \mathrm{a}$ & $1713,13 \mathrm{a}$ & $1,15 \mathrm{a}$ & $\mathrm{S}$ \\
\hline 35 & $9,67 \mathrm{a}$ & $9,43 \mathrm{a}$ & $1637,01 \mathrm{a}$ & $1,10 \mathrm{a}$ & $\mathrm{S}$ \\
\hline 36 & $3,17 \mathrm{a}$ & $6,10 \mathrm{a}$ & $322,20 \mathrm{~b}$ & $0,21 \mathrm{~b}$ & $\mathrm{R}$ \\
\hline 37 & $6,20 \mathrm{a}$ & $9,73 \mathrm{a}$ & $256,32 \mathrm{~b}$ & $0,17 \mathrm{~b}$ & $\mathrm{R}$ \\
\hline 38 & $12,89 \mathrm{a}$ & $2,47 \mathrm{a}$ & $1548,42 \mathrm{a}$ & $1,04 \mathrm{a}$ & $\mathrm{S}$ \\
\hline 39 & $5,43 \mathrm{a}$ & $5,06 \mathrm{a}$ & $1531,94 \mathrm{a}$ & $1,02 \mathrm{a}$ & $\mathrm{S}$ \\
\hline 40 & $12,67 \mathrm{a}$ & $5,24 \mathrm{a}$ & $1946,57 \mathrm{a}$ & $1,30 \mathrm{a}$ & $\mathrm{S}$ \\
\hline 41 & $12,89 \mathrm{a}$ & $12,53 \mathrm{a}$ & $381,42 \mathrm{~b}$ & $0,26 \mathrm{~b}$ & $\mathrm{R}$ \\
\hline 42 & $3,46 \mathrm{a}$ & $3,88 \mathrm{a}$ & $2166,90 \mathrm{a}$ & $1,44 \mathrm{a}$ & $\mathrm{S}$ \\
\hline 43 & $6,10 \mathrm{a}$ & $8,82 \mathrm{a}$ & $1612,03 \mathrm{a}$ & $1,08 \mathrm{a}$ & $\mathrm{S}$ \\
\hline 44 & $7,78 \mathrm{a}$ & $4,67 \mathrm{a}$ & $1664,64 \mathrm{a}$ & $1,10 \mathrm{a}$ & $\mathrm{S}$ \\
\hline 45 & $6,25 \mathrm{a}$ & $12,18 \mathrm{a}$ & $318,62 \mathrm{~b}$ & $0,21 b$ & $\mathrm{R}$ \\
\hline 46 & $11,22 \mathrm{a}$ & $15,13 \mathrm{a}$ & $496,40 \mathrm{~b}$ & $0,34 \mathrm{~b}$ & $\mathrm{R}$ \\
\hline
\end{tabular}

IG = incidência de galhas; NGSR = número de galhas no sistema radicular; NO = número de ovos; FR = fator de reprodução; Médias seguidas da (s) mesma (s) letra (s) na coluna não diferem entre si pelo teste de Scott-Knott a $\mathrm{p}>0,05$ de probabilidade.

${ }^{1} \mathrm{FR}<1=\operatorname{resistente}(\mathrm{R})$ e FR $>1$ = $\operatorname{susceptível~}(\mathrm{S})$. 
Das 46 progênies avaliadas, 36 progênies produziram uma menor quantidade de ovos com FR < 1 (resistentes) a apenas 10 progênies $(25,29,34,35,38,39,40,42,43$ e 44) apresentaram FR > 1 (susceptíveis) promovendo aumento da população do patógeno, segundo a escala de Oostenbrink (1966) (Tabela 2). Houve comportamento coincidente entre os resultados do teste de agrupamento e escala de Oostenbrink (1966). Apenas as progênies 3, 4, 5, 22 e 23 tiveram comportamento divergente, isto é, foram resistentes pela escala de reação de resistência e estão em grupos opostos pelo teste de agrupamento. Mesmo os testes tendo origem completamente adversa essa coincidência corrobora com os resultados encontrados. Considerando progênies de meiosirmãos, o número elevado de progênies resistentes facilitaria o processo de seleção com a utilização da seleção recorrente entre progênies de meios-irmãos. Ademais, a herdabilidade no sentido amplo elevada e o coeficiente de variação genético próximo a 1 recomendam a seleção para este caráter.

As correlações ambiental, fenotípica e genética entre os caracteres índice de galhas e número de galhas no sistema radicular foram positivas e significativas, indicando que tais caracteres são afetados pela variação ambiental de modo coincidente e que os genes que controlam os dois caracteres estão ligados ou trata-se de pleiotropia, o mesmo gene controla os dois caracteres. O caráter número de ovos, não se correlacionou significativamente com índice de galhas, mas sim com número de galhas no sistema radicular, apresentando uma correlação fenotípica e genética de 0,53 e 0,66 respectivamente (Tabela 3 ).

Tabela 3. Correlações ambientais, fenotípicas e genéticas para as características incidência de galhas (IG), número de galhas no sistema radicular (NGSR), número de ovos (NO) e fator de reprodução (FR) em progênies de meios-irmãos de coentro, inoculadas com Meloidogyne incognita raça 1.

\begin{tabular}{|c|c|c|c|}
\hline Características & & NGSR & NO \\
\hline \multirow{3}{*}{ IG } & Variância Ambiental & $0,46 * *$ & 0,10 \\
\hline & Variância Fenotípica & $0,52 * *$ & 0,21 \\
\hline & Variância Genética & $0,62^{+}$ & 0,32 \\
\hline \multirow{3}{*}{ NGSR } & Variância Ambiental & - & 0,20 \\
\hline & Variância Fenotípica & - & $0,53 * *$ \\
\hline & Variância Genética & - & $0,66^{++}$ \\
\hline
\end{tabular}

*** Significativo a $\mathrm{p}>0,05$ e $\mathrm{p}<0,01$ de probabilidade pelo teste $\mathrm{t}$.

${ }^{+++}$Significativo pelo método de Bootstrap com 5000 simulações a $\mathrm{p}>0,05$ e $\mathrm{p}<0,01$ de probabilidade, respectivamente.

$\mathrm{Na}$ análise do coeficiente de coincidência entre os caracteres avaliados, considerando-se uma porcentagem de amostragem de $50 \%$ em relação ao aumento e a diminuição do valor de cada característica, foram obtidos coeficientes de coincidência entre $21,36 \%$ e $71,84 \%$ (Tabela 4). Os maiores valores foram entre incidência de galhas e fator de reprodução sendo igual a 71,84\%, confirmando elevada equivalência entre tais caracteres. $\mathrm{O}$ coeficiente de coincidência entre o número de galhas no sistema radicular e número de ovos foi de $52,43 \%$, próximo à correlação fenotípica entre estes que foi igual a $0,53(53 \%)$ (Tabela 3). Mesmo sendo elevado o coeficiente de coincidência entre índice de galhas e fator de reprodução, o primeiro caráter apresenta baixa herdabilidade $(0,37)$ sendo neste caso o número de galhas no sistema radicular um caráter que pode ser útil no processo seletivo, pois embora tenha apresentado um coeficiente de coincidência de $52,43 \%$ com número de ovos, possui herdabilidade alta de 0,61 .

Tabela 4. Coeficientes de coincidência entre as características incidência de galhas (IG), número de galhas no sistema radicular (NGSR), número de ovos (NO) e fator de reprodução (FR) em progênies de meios-irmãos de coentro, inoculadas com Meloidogyne incognita raça 1.

\begin{tabular}{|c|c|c|c|c|c|c|}
\hline \multirow{3}{*}{ Caracteres } & \multicolumn{6}{|c|}{ Coeficientes de coincidência } \\
\hline & \multicolumn{3}{|c|}{$50 \%$ superiores } & \multicolumn{3}{|c|}{$50 \%$ inferiores } \\
\hline & NGSR & NO & FR & NGSR & $\mathrm{NO}$ & FR \\
\hline IG & 22,33 & 38,84 & 71,84 & 29,13 & 37,86 & 71,84 \\
\hline NGSR & - & 52,43 & 33,98 & - & 52,43 & 33,98 \\
\hline NO & & - & 21,36 & & - & 29,13 \\
\hline
\end{tabular}

Uma das dificuldades dos programas de melhoramento genético que visam à resistência a nematoides é a difícil mensuração do número de ovos, sendo esta uma etapa demorada e onerosa. A identificação de caracteres que se correlacionem positivamente com tal variável é uma alternativa a ser utilizada na seleção indireta nas etapas iniciais dos programas de melhoramento. Embora a correlação fenotípica $(0,53 * *)$ e genética $\left(0,66^{++}\right)$entre número de ovos e número de galhas no sistema radicular não seja alta, é acima de $50 \%$, podendo ser o número de galhas no sistema radicular uma variável a atender as necessidades dos primeiro ciclos seletivos visando a obtenção de progênies resistentes ao $M$. incognita raça 1 . Sendo indispensável à avaliação do número de ovos em programas com populações que já foram submetidas a ciclos de seleção.

Com base nos resultados obtidos, foi possível selecionar 31 progênies que apresentaram $\mathrm{FR} \leq 0,36$ (Tabela 2), levando em consideração que houve formação de dois grupos pelo teste de Scott-Knott (Tabela 2) sendo um grupo composto por progênies com $\mathrm{FR} \leq 0,36$ e o outro grupo composto pelas progênies com FR >0,36. Com a seleção das progênies com menor FR, a cada ciclo seletivo ocorrerá o aumento da frequência dos alelos favoráveis responsáveis pela resistência ao patógeno. As progênies selecionadas serão recombinadas 
para originar a nova população $C_{1}$, da qual serão obtidas as progênies que constituirão a população para o novo ciclo seletivo, sendo o processo repetido até obtenção de uma população homogênea com média baixa para o fator de reprodução.

\section{CONCLUSÕES}

Existe variabilidade genética a ser explorada na cultivar Verdão e entre as progênies de meios-irmãos avaliadas no presente estudo, quanto a resistência ao $M$. incognita raça 1 . Embora haja um grande número de progênies com $\mathrm{FR}<1,0$, é fundamental a seleção dentro da população a fim de reduzir a frequência de alelos desfavoráveis, presentes nos genótipos com FR > 1,0 promotores da manutenção e reprodução do patógeno. Desta forma, é possível obter uma população mais homogênea quanto à resistência ao patógeno na população em estudo.

O número de galhas no sistema radicular é uma variável importante à seleção de plantas nos primeiros ciclos seletivos visando à obtenção de progênies resistentes ao fitonematoide.

\section{REFERÊNCIAS}

ALMEIDA, D. Manual de culturas hortícolas. 1.ed. Lisboa: Editorial Presença, 2006. 346p.

BIONDI, C. M.; PRADO, M. D. C.; MEDEIROS, J. E.; PEDROSA, E. M. R.; MOURA, R. M. Tolerância do coentro ao parasitismo do nematoide Meloidogyne incognita raça 1. Nematologia Brasileira, Piracicaba, v.25, n.2, p.239-241, 2001.

BONETI, J. I. S.; FERRAZ, S. Modificação do método de Hussey \& Barker para extração de ovos de Meloidogyne exígua de raízes de cafeeiro. Fitopatologia Brasileira, Brasília, v.6, n.3, p.533, 1981.

BORÉM, A.; MIRANDA, G. V. Melhoramento de plantas. 6.ed. Viçosa: Ed. UFV, 2013. 523 p.

CRUZ, C. D. GENES: o software package for analysis in experimental statistics and quantitative genetics. Acta Scientiarum, Maringá, v.35, n.3, p.271-276, 2013.

DIEDERICHSEN, A. Coriander Coriandrum sativum L. Edinburgh: University Press, 1996. 83p.

DINIZ, G. M. M. Resistência do coentro (Coriandrum sativum L,) à Meloidogyne incognita (Raça 1 e 3) e Meloidogyne javanica. 2012. 56f. Dissertação (Mestrado em Melhoramento Genético de Plantas) - Universidade Federal Rural de Pernambuco, Recife. 2012.

FALUBA, J. S.; MIRANDA, G. V.; LIMA, R. O.; SOUZA, L. V.; DEBEM, E. A.; OLIVEIRA, A. M. C. Potencial genético da população de milho UFV 7 para o melhoramento em Minas Gerais. Ciência Rural, Santa Maria, v.40, n.6, p. 1250-1256, 2010.

FERRAZ, L. C. C. B.; BROWN, D. J. F. Nematologia de plantas: fundamentos e importância. Manaus: Norma Editora, 2016. $251 \mathrm{p}$.
FERREIRA, S.; GOMES, L. A. A.; GASPARINO, C. F.; CARVALHO FILHO, J. L. S.; MALUF, W. R. Caracterização de famílias $\mathrm{F}_{2: 3}$ de alface para resistência ao nematoide das galhas. Revista Agrogeoambiental, Pouso Alegre, v.5, n.2, p.35-42, 2013.

HUSSEY, R. S.; BARKER, K. R. A comparison of methods colleting inocula of Meloidogyne spp. including a new technique. Plant Disease Reporter, v.57, p.1025-1028, 1973.

INMET. Instituto nacional de meteorologia. 2016. Disponível em:

http://www.inmet.gov.br/portal/index.php?r=bdmep/bdmep. Acesso em: 04 Abr. 2016.

NEFFATI, M.; SRITI, J.; HAMDAOUI, G.; KCHOUK, M. E.; MARZOUK, B. Salinity impact on fruit yield, essential oil composition and antioxidant activities of Coriandrum sativum fruit extracts. Food Chemistry, [S.1.], v.124, n.1, p. 221-225, 2011.

OLIVEIRA, C. M. G. Palestra: Panorama das doenças e pragas em horticultura, doenças causadas por nematoides. Biológico, São Paulo v.69, n.2, p.85-86, 2007.

OLIVEIRA, E. Q.; BEZERRA NETO, F. B.; NEGREIROS, M. Z.; BARROS JÚNIOR, A. P.; FREITAS, K. K. C.; SILVEIRA, L. M.; LIMA, J. S. S. Produção e valor agroeconômico no consórcio entre cultivares de coentro e de alface. Horticultura Brasileira, Brasília, v.23, n.2, p.285-289, 2005.

OLIVEIRA, N. S.; CARVALHO FILHO, J. L. S.; SILVA, D. O.; PASTORIZA, R. J. G.; MELO, R. A.; SILVA, J. W.; MENEZES, D. Seleção e parâmetros genéticos de progênies de coentro tolerantes ao calor. Horticultura Brasileira, Vitória da Conquista, v.33, n.3, p.319-323, 2015.

OOSTENBRINK, M. Major characteristics of the relation between nematodes and plants. Mededelingen Van De landbouwhogeschool, Nederland, v.66, n. 4, p.1-46, 1966.

PINHEIRO, J. B.; PEREIRA, R. B. Manejo de nematoides na cultura do coentro e salsinha. Brasília: Embrapa Hortaliças, 2016. 10p.

SAMOJLIK, L.; LAKIC, N.; MIMICA-DUKIC, N.; DAKOVIC-SVAJCER, K.; BOZIN， B. Antioxidant and hepatoprotective potential of essential oils of coriander (Coriandrum sativum L,) and caraway (Carum carvi L,) (Apiaceae). Journal of Agricultural and Food Chemistry, [S.1.], v.58, n.15, p.8848-8853, 2010.

TIHOHOD, D. Nematologia agrícola aplicada. 2.ed. Jaboticabal: FUNEP, 2000. 372p.

WESEMAEL, W. M. L.; VIAENE, N.; MOENS, M. Rootknot nematodes (Meloidogyne spp.) in Europe. Nematology, [S.1.], v.13, n.1, p.3-16, 2011. 